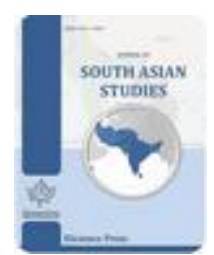

Available Online at EScience Press

Journal of South Asian Studies

ISSN: 2307-4000 (Online), 2308-7846 (Print)

https://esciencepress.net/journals/JSAS

\title{
Relationship Between Surface Dew Point Temperature and Satellite Based Total Water Vapor Content over North Indian Ocean
}

\author{
C. Purna Chand ${ }^{a}$, M.V. Raob, K.V.S.R. Prasad ${ }^{c}$ \\ a National Remote Sensing Centre, Hyderabad, India, and Andhra Pradesh State Disaster Management Authority, Guntur, India. \\ b National Remote Sensing Centre, Hyderabad, India. \\ c Department of Meteorology and Oceanography, Andhra University, Visakhapatnam, India.
}

*Corresponding Author Email ID: purnachandch@gmail.com

\section{A B S T R A C T}

The dew point temperature is related to the total water vapor content available in the atmosphere column. In this study, Water Vapor Content (WVC) from Tropical Rainfall Measuring Mission (TRMM) Microwave Imager (TMI) and Relative humidity from Research Moored Array for African-Asian-Australian Monsoon Analysis (RAMA) buoy data has been utilized to make a relationship between satellite measured WVC and Dew point temperature. This study focuses on the development of an algorithm to estimate the surface dew point temperature from satellite-based WVC. Regression coefficients are established using 9-years (2004-2012) data of Dew point Temperature computed from Relative humidity and satellite measured WVC. 1594 data points are observed weekly, mean monthly collocated data points are considered to examine the relationship between Dew point temperature and WVC.

Keywords: Dew Point temperature, Water Vapor Content, Satellite.

\section{INTRODUCTION}

Dew point temperature or surface moisture content is one of the important parameters in the estimation of evaporation rates over the oceans. Heat supplied by the tropical oceans through evaporation is utilized for the development of large-scale weather systems. The turbulent motion in the lower atmosphere effects the evaporation, it is dependent upon the low-level vertical moisture gradient and the surface winds. There is no satellite sensor which directly measures the dew point temperature. Hence, need to find out a method to estimate the dew point temperature or relative humidity from available satellite data. The surface level humidity is an indicator of dew point temperature; many researchers studied the relationship between the logarithmic water vapor content and the dew point temperature, reported that wvc and dewpoint temperatures are highly correlated (Reitan 1963, Bolsenga 1965, Smith 1966, Lowry and Glahn 1969, Tomasi 1981, Liu and Niiler 1984., Liu 1986, Rao et al. 1986, Mears 2007.). Rietan (1963) carried out a study on the relation between the mean monthly total water vapor content and surface dew point temperature; in this study, he found that the correlation coefficient is 0.98 between total water vapor content and surface dew point temperature. As well as Bolsenga (1965) carried out the same study between mean daily and hourly parameters. He concluded that the mean daily data yielded better correlation compared to the hourly data. Smith (1966) found the errors are as large as $50 \%$ based on mean monthly data and suggested considering the latitudinal and seasonal dependency.

All these studies carried out in the view of measurements of total perceptible water over oceans is very difficult, hence the estimation of this parameter can be made possible through the measurement of surface dew point temperature. The total water vapor content estimations made possible with the satellite measurements (Hollinger 1990, Melsheime 2008). Estimation of dew point temperature is inevitable to compute evaporation rates over the oceans using satellite data. Liu and Niiler (1984) and Rao et al., (1986) 
had an attempted retrieval of dew point temperature from satellite measured total water vapor content. Lu (2007) carried out a study that the relationships between water vapor and temperature through theoretical analysis.

In this study, we made an attempt to develop the relationship between the total water vapor content and the dew point temperature over the North Indian Ocean using collocated data set created with RAMA buoy data (https://www.pmel.noaa.gov/tao/drupal/disdel) and TMI data (https://www.remss.com/missions/tmi). North Indian Ocean has complemented with extraordinary phenomena such as Somali current, equatorial jets, the western boundary current or east India current, monsoon winds and formation of tropical cyclones, etc, because of these conditions we attempted in North Indian Ocean region. Small work has been carried out in this region (Rao et al., 1986). Based on this case we attempted here to understand the relationship between total water vapor content and dew point temperature using RAMA buoy data and TMI data.

\section{DATA AND METHODOLOGY}

Previous studies have proven that Moisture contains in the atmosphere is more at the surface and decreases with height (Reitan, 1963 and Smith, 1966). It implies that the moisture in the atmosphere has some uniform lapse rate. The formula for computing integrated Water

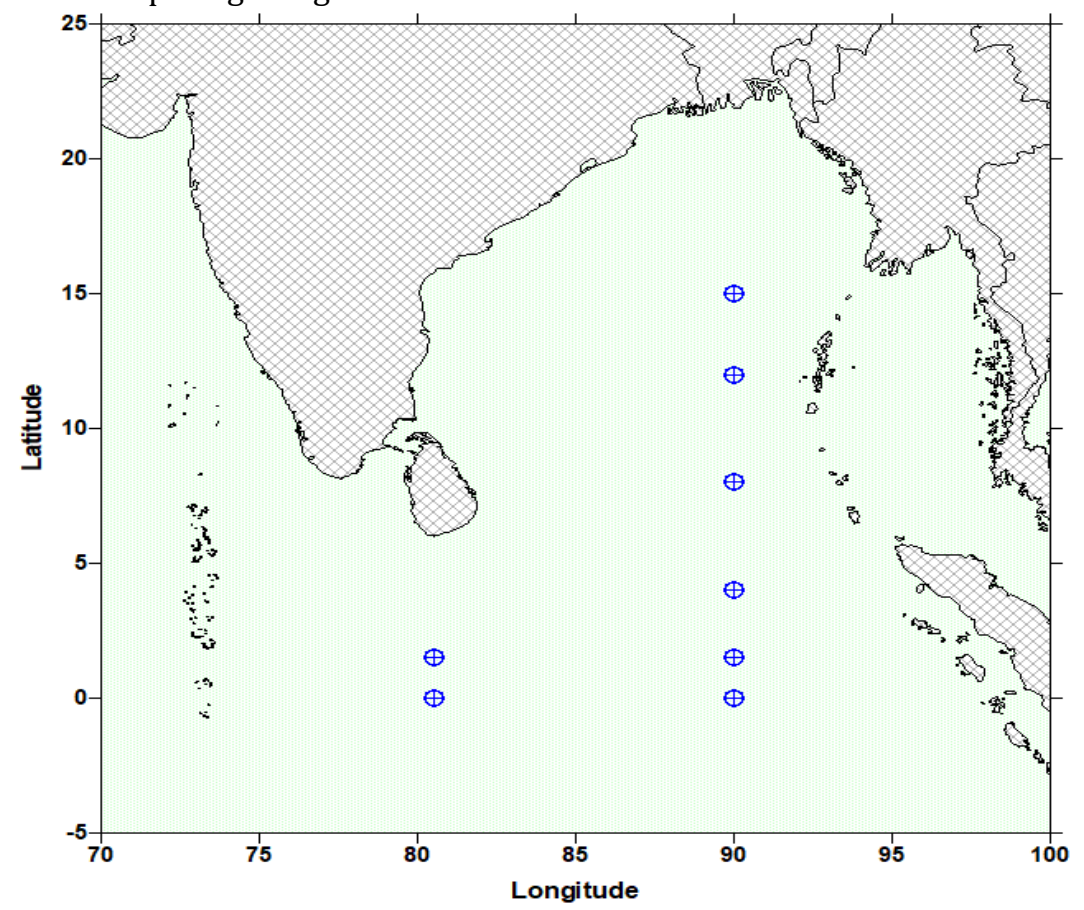

Figure 1. RAMA Buoy Locations in the North Indian Ocean.
Vapor Content (WVC) is;

$$
W V C=\int_{0}^{z} \rho_{w} d z
$$

Where ' $z$ ' is the height of the atmospheric column, ' $\rho w$ ' is specific humidity of the layers and ' $\mathrm{dz}$ ' is the layer height.

Based on the literature, the dew point temperature (Td) is related to WVC as follows.

$$
T_{d}=A+B \ln (W V C)
$$

Where the coefficients of ' $A$ ' and ' $B$ ' are obtained by the least square optimization fit of collocated points of $\mathrm{Td}$ and WVC. Atmospheric Moisture profiles are highly variable in spatial and temporal, particularly in North Indian Ocean region due to very localized weather conditions; we have made a collocated database for the North Indian Ocean. Acquired relative humidity from RAMA buoys during 2004-2012 over North Indian Ocean region. From this buoy data, we computed the dew point temperature using the method given by Mark (2005) and Tetens (1930) coefficients. Weekly and monthly WVC data have been acquired from TMI and collocated data has been prepared. The daily RAMA buoy relative humidity data made as weekly and monthly with correspondence to TMI data. This database was considered to study the relationship between dew point temperature and WVC. Buoy locations in the North Indian Ocean region are presented in figure-1 which is used for study the relation. 


\section{RESULTS AND DISCUSSION:}

During the study period 2004-2012, 1594 collocated data points are observed. In the month of June, the minimum (100) and month of December maximum (183) data points are observed. With these whole data points, we generated the statistics for weekly, monthly and seasonally, the coefficient of determination $\left(R^{2}\right)$ (hereafter CD) also computed and presented in table 1. In statistics, $\mathrm{CD}$ indicates how much closer the data to each other. From the table 1 , the $\mathrm{R}^{2}$ value is as high as 0.811 in the month of January and is low in October as 0.05 . 380 collocated data points ware observed in the monthly database.

Table 1. Weekly, Monthly and Season wise statistics on the relationship of dew point and WVC.

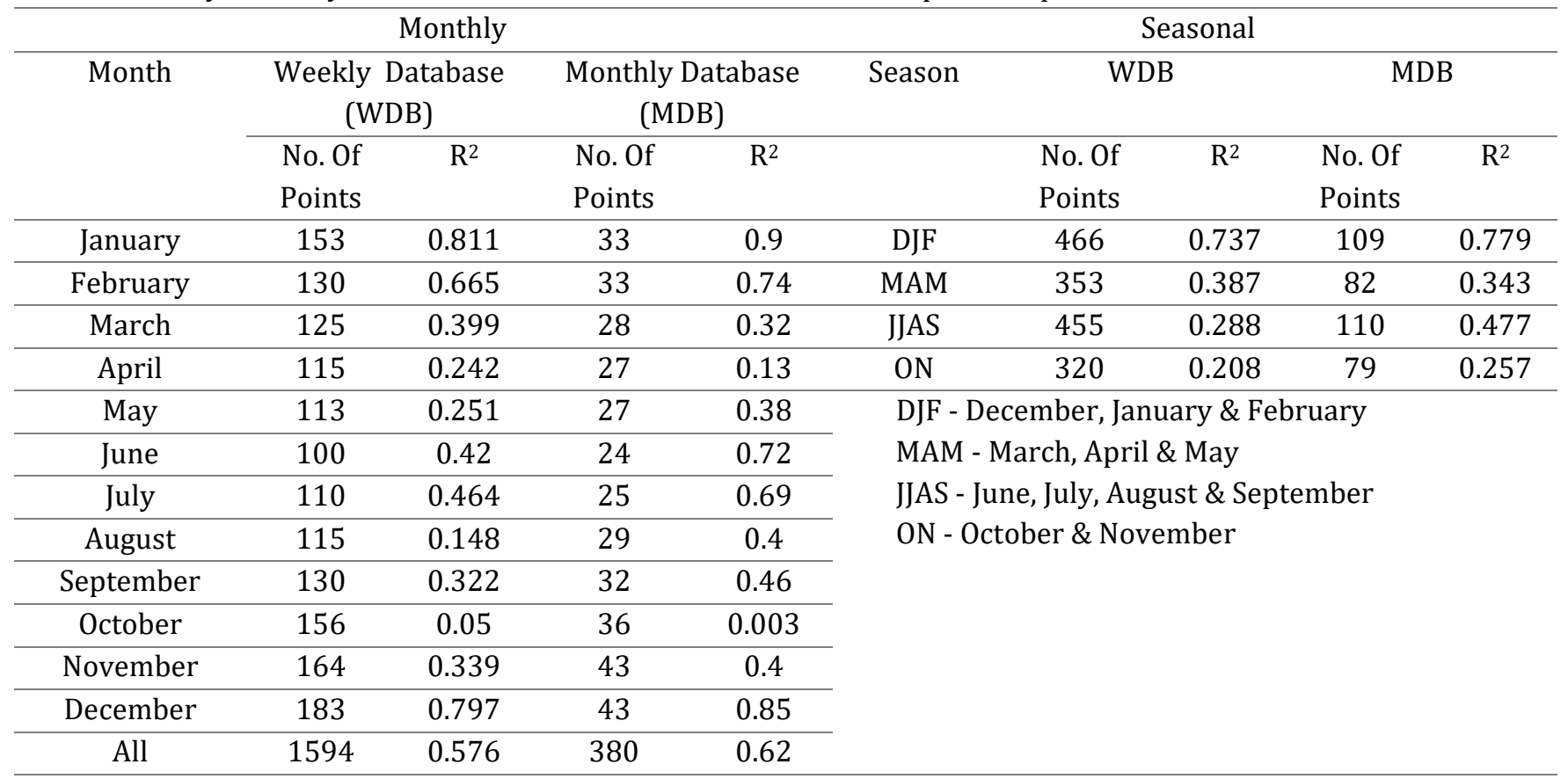

We divided the database into 4 seasons like December, January and February (DJF or winter), March, April and May (MAM or summer), June, July, August and September (JJAS or monsoon) and October, November (ON or post-monsoon) with monthly and weekly data. $\mathrm{CD}$ is quite good during winter (monthly data wise $\mathrm{R} 2=0.78$ ) as well as poor (weekly data wise $\mathrm{R} 2=0.21$ ) during post monsoon. When studying the moisture profiles, the specific humidity will be high in the upper layers during monsoon and the post-monsoon period and it is not pseudo-adiabatic as assumed. This could be due to the moisture pumping from the surface during monsoon and cyclonic activities (October \& November). The CD value is 0.576 for weekly data and improved for monthly data to 0.617 . The scatter diagram for the whole data with weekly and monthly are presented in figure 2 . The estimated coefficients of 'A \& B' are 4.679 and 5.069 from the total monthly data set. It is a known fact that the values are averaged over a month, the errors in the moisture profile were minimized; hence the values are improved from weekly to monthly. Logarithmic WVC is spread between 2.7 and 4.5 during the winter (DJF), whereas these values are confining to 3.7 to 4.7 during monsoon (JJAS). This reveals that the moisture content is high and narrow distribution during monsoon. The high CD during winter indicates that the surface dew point is representing the total perceptible water and the coefficients are estimated as $A=3.445$ and $B=5.327$. The poor CD during monsoon and post-monsoon is due to high moisture in the upper levels of the atmosphere, this leads to a low relationship between surface dew point and WVC. Vertical distribution of humidity over Minicoy Island during January and June has been explained by Rao et al., (1986). He showed that in-general the humidity is higher in June compared to January and its difference is larger when approached to higher altitudes (about $700 \mathrm{mb}$ ). Its general observation that the moisture content is high in the upper layers during the 
cyclone period compared to normal conditions. In October and November, the tropical cyclones are more in the Bay of Bengal, hence we assumed that the poor coefficient of determination observed.
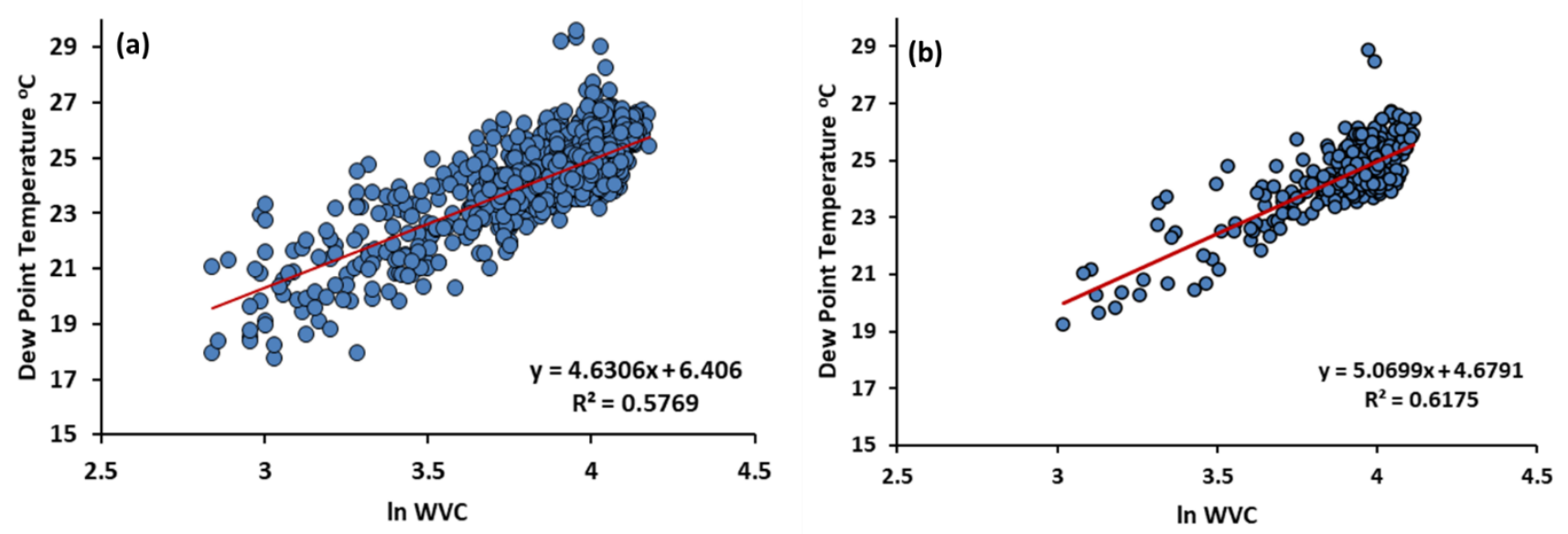

Figure 2. Scatter diagram between the Logarithm of WVC and Dew Point Temperature for the whole dataset weekly (a) and monthly (b).

\section{CONCLUSIONS}

The coefficients of 'A and B' are derived from the monthly data set is found to be suitable for the estimation of dew point temperature, with a CD of 0.617 for the WVC and dew point temperature.

During winter the relationship found to be good, indicating that the surface dew point temperature is representing the WVC, whereas poor correlation during monsoon and post-monsoon are due to failure of the assumption of the pseudo-adiabatic lapse rate.

The estimation of dew point temperature can be made from satellite-based WVC with the equation developed using the total monthly data set. However, the winter equation can be suggested for December, January and February months. The weekly database generated coefficients also can be used for estimation of weekly dew point temperature since the weekly and monthly correlations are found to be closer.

\section{ACKNOWLEDGEMENTS}

This work was carried out at the National Remote Sensing Centre (NRSC), as a part of the Technology Development program. TMI data are produced by Remote Sensing Systems and sponsored by the NASA Earth Sciences Program is used in this study. The RAMA buoy data collected from Tropical Atmosphere Ocean Project, Pacific Marine Environmental Laboratory (PMEL), National Oceanic and Atmospheric
Administration (NOAA). Authors have no conflicts of interest to disclose. Authors are thanking Oceanography group, NRSC for their extended support.

\section{REFERENCES}

Bolsenga, S. J., (1965) The Relationship between Total Atmospheric Water Vapor and Surface Dew Point on a mean daily and hourly basis, J. Appl. Meteor., 4, 430-432.

Hollinger, J. P., J. L. Pierce, and G. A. Poe., (1990) SSM/I instrument evaluation, IEEE Trans. Geosci. Remote Sensing, 28(5), 781-790.

Liu, W. T. and P. P. Niiler., (1984) Determination of Monthly Mean humidity in atmospheric surface layer over oceans from satellite data, J. Phys. Oceanogr., 14, 1451-1457.

Liu, W. T., (1986). Statistical Relation between Monthly Mean Precipitable Water and surface level humidity over global oceans, Mon. Wea. Rev., 114, 1591-1602.

Lowry, D. A. and H. R. F. Glahn., (1969) Relation between integrated atmospheric moisture and surface weather, J. Appl. Meteor., 8, 762-768.

Lu, Er., (2007). Understanding the effects of atmospheric circulation in the relationships between water vapor and temperature through theoretical analyses Geophysical Research Letters, vol. 34, L14811, doi:10.1029/2007GL029727. 
Mark G. Lawrence., (2005) The Relationship between Relative Humidity and the Dewpoint Temperature in Moist Air: A Simple Conversion and Applications. Bull. Amer. Meteor. Soc., 86, 225233.

Mears, C. A., B. D. Santer, F. J. Wentz, K. E. Taylor, and M. F. Wehner., (2007) Relationship between temperature and percipitable water changes over tropical oceans, Geophysical Research Letters, vol. 34, L24709, doi:10.1029/2007GL031936.

Melsheimer, C. and G. Heygster., (2008) Improved Retrieval of Total Water Vapor Over Polar Regions from AMSU-B Microwave Radiometer Data, IEEE Trans. Geosci. Remote Sensing, 46 (8), 2307-2322.
Rao, M. V., V. Ramesh Babu, L. V. G. Rao, and J. S. Sastry., (1986) Estimation of evaporation rates over the Arabian sea from satellite data. Proc. Of Ind. Acad. Of Sci., 95(3), 417-426.

Reitan, C. H., (1963) Surface dew point and water vapor aloft, J. Appl. Meteor., 2, 776-779

Smith, W. L., (1966) Note on the relationship between total precipitable water and surface dew point, J. Appl. Meteor., 5, 726-727.

Tetens, O. (1930) Uber einige meteorologische Begriffe. Z. Geophys.. 6. 297-309.

Tomasi, C., (1981) Determination of the Total Precipitable Water by Varying the Intercept in

Reitan's Relationship, J. Appl. Meteor., 20, 1058-1069.

Publisher's note: EScience Press remains neutral with regard to jurisdictional claims in published maps and institutional affiliations.

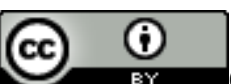

Open Access This article is licensed under a Creative Commons Attribution 4.0 International License, which permits use, sharing, adaptation, distribution and reproduction in any medium or format, as long as you give appropriate credit to the original author(s) and the source, provide a link to the Creative Commons license and indicate if changes were made. The images or other third-party material in this article are included in the article's Creative Commons license, unless indicated otherwise in a credit line to the material. If material is not included in the article's Creative Commons license and your intended use is not permitted by statutory regulation or exceeds the permitted use, you will need to obtain permission directly from the copyright holder. To view a copy of this license, visit http://creativecommons.org/licenses/by/4.0/.

(C) The Author(s) 2021. 